\title{
Tokoh Bambang Ekalaya dan Moralitas Pendidikan
}

\author{
AGUS PRASETYA* \\ Jurusan Teater, Fakultas Seni Pertunjukan, Institut Seni Indonesia Yogyakarta.
}

\begin{abstract}
Bambang Ekalaya and The Education Morality. Si Bambang Ekajaya is a story that is produced from the education morality condition that is growing in society at this time, and than commuted be a play manuscript story, it means that the appraise these are justification and contraction. It can also be said as criticism what are looked and heard as a respond. The creation of Si Bambang Ekajaya used inter-textual theory, which inter-textual theory is to find some aspects which have already exist in the works before, which appears more in the text. From some aspects, inter-textual principle can also be connected to literature work reception.
\end{abstract}

Key words: Morality, Inter-textual, Reception

\section{Pendahuluan}

Pengertian mengenai pendidikan yang lazim dikenal adalah proses pemahaman tentang sesuatu yang dikelola oleh sebuah lembaga dengan istilah pendidikan formal dan nonformal. Namun makna pendidikan secara luas tidaklah demikian karena pendidikan adalah proses pembelajaran; pembelajaran adalah proses pemahaman. Ini berarti pendidikan adalah proses pemahaman atas segala sesuatu yang dihadapi manusia. Dengan demikian. pendidikan bukan hanya yang dikelola oleh suatu lembaga tetapi termasuk pula suri teladan, petuah dan lain sebagainya, baik melalui media (cetak dan elektronik) maupun langsung secara lisan. Namun kenyataannya sebagian besar media yang ada di Indonesia kurang memiliki niatan untuk mendidik, bahkan cenderung memiliki dampak yang kurang baik.

Sementara itu, situasi dan kondisi dunia pendidikan formal dewasa ini sedang memasuki fase yang sangat memprihatinkan. Sebagai contoh kasus adalah fenomena pendidikan yang terjadi di Yogyakarta. Lembaga pendidikan nonformal (terutama bimbingan belajar) tumbuh subur bahkan secara kuantitas peminatnya jauh melebihi jumlah peminat pendidikan formal. Lebih ironis lagi bahwa sebagian besar siswa pendidikan formal juga sebagai peserta pendidikan non formal. Bukan hanya sekolah-sekolah yang memiliki "kualitas" sedang ke bawah, akan tetapi siswa sekolah favorit pun tidak ketinggalan. Kasus demikian apabila dicermati terdapat dua sisi yang kontradiktif. Satu sisi sangat menggembirakan bahwa masyarakat Indonesia memiliki "kesadaran kualitas" atas pendidikan anak-anaknya. Sisi lain yang justru memprihatinkan adalah sebagai bukti bahwa masyarakat Indonesia sudah tidak "percaya" lagi kepada kemampuan lembaga pendidikan formal untuk memenuhi tuntutan pendidikan generasi mendatang.

Kemunculan fenomena pendidikan demikian tersebut di atas dilatarbelakangi karena perubahan pandangan masyarakat Indonesia mengenai "makna sekolah". Orientasi sebagian besar orang tua adalah mengejar nilai yang bagus dalam rangka mendapatkan rangking. Pemahaman tentang materi pelajaran bukan sebagai prioritas tuntutan. Demikian halnya dengan siswa sendiri juga berorientasi pada pencapaian nilai yang bagus. Pada sisi lain peraturan pemerintah pun tidak menuntut siswa untuk memahami materi pelajaran. Apabila ada sekolah yang persentasi siswanya tidak naik atau tidak lulus melebihi batas peraturan yang telah ditentukan maka akan

\footnotetext{
* Alamat korespondensi: Jln. Parangtritis KM. 6,5 Sewon,Yogyakarta. Tlp. 0274-375380, Kotak Pos 1284 Yogyakarta - 55001. e-mail: agusleylor@yahoo.co.id
} 
mendapat teguran. Hal demikian mengakibatkan system pengkatrolan nilai (Dalam lingkup perguruan tinggi dikenal dengan istilah "SP": "Semester Penyelamatan") untuk meminimalisasi kegagalan siswa. Semua itu dilakukan agar terhindar dari teguran atasan serta meningkatkan akreditasi lembaganya. Kondisi demikian akhirnya menciptakan lingkaran setan tentang kemerosotan kualitas pendidikan di Indonesia. Proses sudah tidak mendapat penghargaan lagi, dan akibatnya lembaga-lembaga peningkatan prestasi yang sifatnya "instan" banyak diburu orang tua murid. Dengan kata lain, orientasi pendidikan bangsa ini telah mengalami perubahan yang menyesatkan.

Pendidikan adalah pembelajaran. Pembelajaran adalah langkah untuk mencapai pemahaman. Untuk memahami materi pendidikan diperlukan sebuah proses. Proses memerlukan semangat. Tujuan pendidikan akan tercapai apabila dengan orientasi yang benar. Artinya, orientasi pendidikan akan menumbuhkan semangat serta menuntun pemahaman kita dalam proses pembelajaran. Dengan demikian dapat dikatakan bahwa hakekat pendidikan adalah penghargaan terhadap sebuah proses dan dilandasi dengan orientasi yang benar.

Oleh karena itu, dalam rangka mengkritisi kondisi pendidikan, kita harus meninjau kembali orientasi pendidikan masyarakat kita. Melalui Si Bambang Ekalaya akan tercermin yang dimaksud dengan pendidikan adalah pembelajaran.

Kisah yang dipaparkan dalam karya ini diadopsi dari epos Mahabarata, yaitu Ekalaya yang dalam tradisi pedalangan Jawa dikenal dengan cerita Palguna-Palgunadi yang menceritakan kisah tentang pertentangan antara Palguna (Arjuna) dan Palgunadi (selanjutnya disebut Ekalaya). Sudah barang tentu bahwa dalam sebuah adopsi cerita selalu menemui berbagai persoalan dan tentunya terjadi pula perubahan-perubahan dalam rangka menyesuaikan dengan kebutuhan. Namun demikian, dalam setiap perubahan yang terjadi selalu diusahakan kontinuitas konsep yang ada di dalam kisah Mahabharata agar tidak terjadi diskontinuitas secara total, artinya masih memungkinkan dilakukan pelacakan kembali urutan cerita aslinya pada suatu saat nanti.

Kisah-kisah dalam epos Mahabharata selalu relevan dengan kondisi yang terjadi dalam dunia nyata saat kisah tersebut dipertunjukkan, dan memberikan banyak ruang bagi aspek cerita maupun visual panggung untuk diekspresikan dalam bentuk teater modern. Menurut Jakob Sumardjo, bentuk teater modern ini secara garis besar memiliki ciri-ciri sebagai berikut: (1) Pertunjukan dilakukan di tempat khusus, yakni di panggung prosenium dalam sebuah gedung, (2) Penonton harus membayar. Pada teater tradisional kebiasaan itu tidak pernah ada, karena diselenggarakan di tempat umum dan terbuka, (3) Fungsi teater adalah untuk hiburan. Sedang fungsi teater tradisional adalah upacara yang berhubungan dengan suatu kepercayaan, (4) Unsur cerita teater modern erat kaitannya dengan peristiwa-peristiwa sezaman, dan (5) Menggunakan naskah drama yang tertulis (Jakob Sumardjo, 1992:99-100).

Pada dasarnya alur cerita karya ini sama dengan alur cerita Ekalaya yang telah lebih dahulu ada namun yang membedakan adalah pada penekanan dan sudut pandang (point of view) yang berbeda, juga pada penghadiran tokoh-tokohnya. Diakhir cerita yang sudah pernah ditampilkan, Ekalaya mati sedang Arjuna tetap hidup, sedangkan akhir cerita Si Bambang Ekalaya, Ekalaya tetap hidup dan Arjuna akan tetap mati atau dihidupkan kembali oleh Sri Kresna, diserahkan pada interpretasi masing-masing penonton/pembaca.

Permasalahan yang dihadapi dalam sebuah karya seni pertunjukan paling tidak ada dua persoalan pokok yang harus diperhatikan yaitu aspek cerita dan aspek pertunjukan. Aspek cerita lebih kepada pengertian proses penciptaan naskah drama Si Bambang Ekalaya. Sedangkan aspek pertunjukan merupakan perwujudan dari naskah Si Bambang Ekalaya menjadi bentuk pertunjukan teater.

\section{Aspek Cerita}

Naskah drama Si Bambang Ekalaya ini merupakan hasil resepsi dari Ekalaya Palastra I, II, dan III dalam Seri Mahabharata karya R.A. Kosasih yang berbentuk komik (cerita bergambar). Pada proses penciptaan naskah Si Bambang Ekalaya ini menggunakan kajian intertekstual. "Secara lebih khusus dapat dikatakan bahwa kajian interteks berusaha menemukan aspek-aspek tertentu yang telah ada pada karya-karya sebelumnya pada karya yang muncul lebih kemudian" (Nurgiyantoro, 2002:50). Si Bambang Ekalaya adalah sebuah cerita yang dihasilkan dari merespon teks yang sudah ada yang dibaca atau fenomena yang dijumpai 
seorang penulis, dan kemudian digubah menjadi sebuah cerita (naskah drama); artinya di sini diberlakukan penilaian (pembenaran/penyalahan) atau kritik atas apa yang dilihat dan dibaca, sebagai respon. Kondisi ini sebagai kondisi yang mengubah cerita Ekalaya dari intersubjektivitas teks menjadi ntertekstual. Menjadi intertekstual berarti menangkap persoalan identifkasi cerita Ekalaya. Cerita Ekalaya sebagai teks tidak menempatkan teks-teka secara berdampingan dan saling berpengaruh untuk menghasilkan makna, tetapi justru menunda makna. Prosesnya tidak menyertakan makna teks terdahulu, tetapi sebuah teks bekerja menyerap dan menghancurkan pada saat yang bersamaan teks-teks lain dalam ruang intertekstual.

Dalam rangka kajian teater, empat aspek cerita yang diperhatikan adalah (a) Bentuk fisik naskah, (b) Alur cerita; alur adalah rangkaian peristiwa yang terjadi dalam sebuah cerita, (c) Penokohan; penokohan adalah suatu proses penampilan tokoh sebagai pembawa peran watak. Penokohan erat hubungannya dengan karakter atau perwatakan tokoh, (d) Dialog; dialog dalam naskah drama akan sangat membantu dalam penggarapan ke atas panggung, karena dialog menjadi dasar perubahan suasana adegan demi adegan.

\section{Aspek Pertunjukan}

Kisah Palguna-Palgunadi menjadi Si Bambang Ekalaya menggunakan konsep estetika teater modern Indonesia baik pada aspek cerita maupun pada aspek pemanggungannya. Estetika teater modern Indonesia yang saya maksud di sini adalah mengacu pada unsur-unsur estetika yang disampaikan Djelantik, semua benda atau peristiwa kesenian mengandung tiga aspek dasar (1) Wujud atau rupa, visual dan akustik (2) Bobot atau isi (suasana, ide dan pesan), dan (3) penampilan: mengacu pada pengertian bagaimana cara kesenian disajikan pada penonton (Djelantik, 2001:15-67).

Aspek pertunjukan dalam karya teater antara lain adalah sebagai berikut (1) Penyutradaraan. Pengertian sutradara adalah orang yang bekerja berdasarkan konsep dan mampu mengorganisasi produksi, juga dapat menjalin kerjasama dan komunikasi yang baik dalam hubungannya dengan sekelompok aktor, perancang artistik dan juga teknisi untuk menghasilkan sebuah pementasan teater. (2) Pemeranan. Yakni tentang tata cara memerankan tokoh dalam sebuah cerita. (3) Tata Artistik. Tata artistik adalah sebuah wilayah penting dalam disiplin seni pertunjukan. Tidak ada satu jenis seni pertunjukan pun yang berani dan bersedia melupakan tata artistik. Satu hal disebabkan seni pertunjukan tidak bisa mengelakkan diri dari dimensi ruang dalam ekspresinya. Ruang dalam pengertiannya sebagai area dan latar permainan yang tidak terhindarkan kehadirannya. Meski begitu kehadiran bendabenda di atas panggung menjadi berarti atau bermakna tergantung pada kemampuan dan kreativitas pemeran dalam menghidupkannya.

Kalau para pelaku dan pemeran bisa merespon dan tidak merasa asing terhadap benda-benda yang mengelilinginya (skeneri) maka 'hidup' dan jumbuh-lah tata artistik panggung dengan keseluruhan elemen hidup teater dan irama musikalnya (LeyLoor, 2003:86)

(4) Musik. Musik dibedakan menjadi musik sebagai iringan, sebagai ilustrasi, dan sebagai efek bunyi yang berfungsi untuk membangun suasana dramatik. Konsep penggarapan karya ini ada dua, yaitu konsep perwujudan cerita dan konsep perwujudan tata teknik pentas.

Pada konsep penciptaan cerita terjadi pembongkaran teks dari teks asli Ekalaya Palastra I, II, III karya R.A. Kosasih menjadi Si Bambang Ekalaya. Perubahan secara fisik yakni dari cerita bergambar atau komik menjadi naskah drama panggung yang kemudian ditransformasikan ke atas panggung berupa pementasan teater. Di sini terjadi dekonstruksi. "Dekonstruksi adalah suatu metode pembacaan teks secara teliti, yaitu dengan menginterogasi teks, merusaknya melalui pertahanannya, dan mencari oposisi biner yang tertulis di dalam teks" (Rengganis, 2004:89).

Dalam rangka ini terdapat dua tegangan permasalahan yakni sebagai berikut: (a) Paradigma. Paradigma cerita Palguna-Palgunadi yang ada selama ini selalu dari sisi Harjuna sebagai hero, pahlawan. Dalam karya ini, paradigma itu dibalik, yakni dari sisi Ekalaya,dengan kata lain keberpihakan lebih kepada Ekalaya. (b) Karakterisasi Tokoh. Penentuan karakter tokoh dalam drama ini tidak menggunakan karakter wayang secara utuh, melainkan dideformasi, yakni perubahan bentuk bagian badan manusia 
disesuaikan dengan tujuan karya namun tidak meninggalkan sama sekali karakter wayang. (5) Teknik pentas. Teknik pentas meliputi hal-hal yang berkenaan dengan tata cara atau proses jalannya pementasan, baik meliputi struktur cerita, struktur adegan, penokohan, penciptaan konflik, dan sejenisnya. (6) Tata pentas. Tata pentas yakni physical setting (tata panggung, tata lampu dan sebagainya) dan actor setting. Kehadiran tata pentas sangat menentukan rangka pengembaraan imajinasi penonton. Artinya: tata pentas kadangkadang membelenggu pengembaraan imajinasi penonton, atau justru memberi kebebasan yang absolut. Tata pentas dalam karya ini dibuat setting tunggal. Hal ini bertujuan untuk memberikan kebebasan pengembaraan imajinasi penonton seluas-luasnya.

\section{Pembahasan}

Menuntut ilmu, "belajar" artinya berusaha mendapatkan dan menghasilkan segala macam ilmu dengan cara bertanya, melihat, mendengar baik melalui suatu lembaga atapun melalui pengalaman empirik. Perintah dan kewajiban menuntut ilmu pun telah dianjurkan sejak jaman nabi. Hadist Nabi Muhammad dalam HR. Ibn Abdulbari menyebutkan bahwa menuntut ilmu adalah fardlu, hukumnya wajib bagi tiap-tiap umat manusia baik laki-laki maupun perempuan (Rifài, 1978:11). 1)

Petikan dialog dalam Si Bambang Ekalaya (hal.

001. Ekalaya $\quad$ Nama hamba Ekalaya, putra
Raja Nisada Eyang.

002. Resi Durna: Oh, sebuah tempat yang sangat jauh di ujung India... Lantas, apa maksud kedatangan Ananda kemari?

003. Ekalaya : Kedatangan hamba menghadap Eyang, tak lain ingin berguru ilmu Danurweda.(ilmu memanah)

Ekalaya sebagai manusia yang berakal dan berbudi mempunyai niatan dan tekad menyempurnakan diri dengan belajar menuntut ilmu kepada Durna meski harus melawatkebelahan negara lain. Resi Durna pengelola lembaga yang mengajarkan olah kanuragan (spesialisasi ilmu memanah) dengan murid-murid pilihan keluarga Kurawa dan Pandawa di negeri Hastinapura dapat digambarkan sebagai sebuah lembaga bergengsi yang menarik Ekalaya untuk ikut menjadi salah satu murid yang belajar di dalamnya. Namun Ekalaya tidak memenuhi persyaratan agar dapat diterima menjadi murid Durna, yakni dia bukanlah keturunan darah Kurawa ataupun keturunan Pandawa. Artinya dalam suatu lembaga yang dikelola selalu menerapkan dan diberlakukannya syarat-syarat sebagai formalitas aturan yang telah ditetapkan.

Di sini terjadi suatu pembenaran mitos bahwa Danurweda adalah satu-satunya ilmu pengetahuan memanah yang paling ampuh dan sakti, dan Resi Durna adalah guru memanah tiada duanya. Mitos itu akan terus dianggap berlaku sampai dapat dibuktikan bahwa ia tidak benar. Melalui persentuhan langsung dengan sesuatu yang dimitoskan tadi akan dapat diketahui kebenaran atau kesalahan dari mitos tersebut. Persentuhan ini mungkin dapat memperkuat mitos atau mungkin juga dapat meniadakannya. Karena mitos tidak dibentuk melalui penyelidikan, tetapi melalui anggapan berdasarkan observasi kasar yang digeneralisasikan. Oleh karenanya lebih banyak hidup dalam masyarakat (Junus, 1981:71-101)

067. Ekalaya : Namun dengan patung Eyang itu, hamba telah berhasil 'mengagem' aji seperti yang Eyang miliki.

Itu pertanda bahwa dewata telah merestui. Dan rasanya tidak mungkin hamba dapat berlatih dengan tekun tanpa disaksikan oleh patung Eyang Durna.

Resi Durna dimitoskan oleh Ekalaya dengan cara membuat patung merupakan manifestasi dari pemberi spirit atau semangat dalam mewujudkan impian dan cita-citanya menguasai ilmu Danurweda. Kenyataan, Ekalaya tanpa mengikuti pendidikan dalam suatu lembaga dan tanpa bimbingan guru dalam arti secara fisik yakni kehadiran Durna, ia mampu menguasai ilmu Danurweda melebihi kemampuan yang dimiliki oleh Harjuna. Artinya, di sini Ekalaya melakukan proses belajar secara otodidak. Dalam mendapatkan ilmu pengetahuan ada dua jenis kegiatan yang dilakukan oleh manusia yakni empirik dan tautologi. Empirik adalah pengetahuan yang didapat setelah melalui pengalaman-pengalaman indrawi kemudian diproses oleh akal dan budi kita. Tautologi adalah cara mendapatkan pengetahuan 
bukan dengan pengalaman inderawi, seperti ilmu pasti, ilmu matematika, dan lain sebagainya (Djelantik, 2001:148).

"Suatu paradigma adalah sebuah model ideal, pola, atau contoh yang jelas dan baik dari sesuatu" (Marianto, 2004:34). Bagi Ekalaya, guru merupakan pusat ilmu dan seorang yang harus dipatuhi, ditaati dan ikuti segala perintah dan aturan yang dibuatnya. Guru sebagai panutan yang harus ditaati dan diikuti perilakunya atau dalam masyarakat Jawa dengan "Guru digugu lan ditiru" dalam kisah Ekalaya ini tidak berlaku. Mengetahui hanya dengan disaksikan oleh patung dirinya Ekalaya mampu menguasai ilmu Danurweda, dan juga untuk menghilangkan anggapan Harjuna dan saudara-saudaranya bahwa ia telah berkhianat menerima murid selain darah Barata, maka timbul niat jahat Resi Durna untuk memperdaya Ekalaya. Jadi paradigma yang selama ini berjalan dalam masyarakat "Guru digugu dan ditiru" hancur oleh sikap Resi Durna kepada Ekalaya.

Petikan dialog:

073. Resi Durna: Ketahuilah oleh kalian semua. Hari ini Ekalaya telah membuktikan kesaktianku. Dia yang belajar hanya dengan patungku, telah dapat menguasai ilmu memanah yakni Danurweda seperti yang kalian pelajari. Untuk itu, mulai saat ini Ekalaya akan saya akui sebagai murid, apabila dapat memenuhi syarat yang aku ajukan.

076. Ekalaya : Apapun persyaratannya, hamba bersedia melaksanakan, asal eyang mengakui hamba sebagai murid dan guru kepada hamba.

077. Resi Durna: (tegas) Oke! Potonglah kedua ibu jari tanganmu, jika benarbenar ingin menjadi murid Resi Durna.

Tanpa pikir panjang Ekalaya segera mengambil pisau yang berada dipinggang untuk memotong kedua ibu jarinya. Kilat menyambar tiba-tiba, dan kemudian kedua potongan ibu jari itu segera diserahkan kepada Resi Durna sebagai tanda kesetian kepada gurunya. Semua yang menyaksikan terperanjat dan kaget bukan kepalang.
Namun sikap dan tindakan Ekalaya sebagai bukti kesetiaannya pada guru ditanggapi Resi Dorna sebagai suatu tindakan seorang yang bodoh.

079. Resi Durna:... benar-benar ananda Ekalaya ini seorang yang patuh tapi bodoh dan tolol.

... Ketahuilah, bahwa ibu jari itu sebagai penebus dosa atas

kelancanganmu karena telah berani mengaku diriku sebagai gurumu.

... Kepandaianmu telah punah, karena ibu jari tanganmu telah kamu potong. Mana bisa orang membidikkan panah dengan sempurna tanpa bantuan ibu jari?

Sikap Ekalaya yang menempatkan guru pada posisi tertinggi akhirnya hancur karena perilaku Arjuna memaksa Dewi Anggraeni. Harga diri dan kehormatannya sebagai manusia hancur dan terinjak. Ekalaya kehilangan kepercayaan terhadap Resi Durna, guru yang diagungkan setara dengan dewata namun tidak menepati janji, dan memiliki murid berakhlak budi rendah. Maka dihancurkannya patung Resi Durna dengan kemarahan yang meluap.

139. Ekalaya : Rasakanlah berhala tua! Hancurlah segala kemunafikanmu, kesombonganmu, dan segala kelicikanmu! Hyaaat...! Telah kubayar dengan darah dan tubuhku, seberapa banyak ilmu yang kau berikan padaku...? Kini kukembalikan kepadamu... hyaaat...!

Setiap selesai bicara pedangnya disabetkan pada patung Durna hingga hancur berkepingkeping...

Penghancuran patung Resi Dorna merupakan manifestasi dari penghancuran paradigma dan mitos yang selama ini diyakininya. Suatu mitos (anggapan yang diyakini dan dipercayaai kebenarannya) bagaimanapun dominannya ia akan didampingi mitos yang lain sebagai kontramitos. Sebuah mitos dapat dilawan dengan dua cara, yakni (a) mengadakan mitosyang mendemitifikasikannya dan (b) membuktikan bahwa sesuatu mitos itu tidak benar adanya (Junus, 1981:76). 
Selama ini yang sering kita lihat dan dengar dalam pergelaran wayang selalu memandang dari sudut Pandawa yang berakal budi mulia atau selalu berpihak kepada Pandawa sebagai ksatriaksatria pilihan dewa. Tingkah laku yang ideal dan dijadikan contoh bagi orang tua dalam mendidik anak-anaknya adalah para Pandawa. Pandawa merupakan tokoh-tokoh teladan. Bahkan meskipun tokoh Arjuna melakukan tindakan melanggar norma-norma susila, misalnya merusak "pagar ayu" tetap saja dijadikan sebagai pahlawan dan tokoh panutan.

Dalam kisah ini pun sikap dan perilaku yang jauh dari sikap seorang ksatria ditampilkan Harjuna yakni dengan sikapnya memaksa Dewi Anggraeni agar mau dijadikan istri. Sikap penguasaan diri yang selama ini dijadikan teladan tidak mampu dikendalikannya. Bertolak belakang dari gambaran yang diuraikan dalam kakawin Arjunawiwaha bahwa Harjuna adalah seorang ksatria: teguh hati, waspada, setia pada dharma seorang ksatria, memelihara kesejahteraan dunia, berbuat baik pada sesama, selalu menjaga kehormatan, membela hak, dan mahir dalam siasat (Wiryamartana, 1990:456).Sikap dan peri laku wanita yang menjunjung tinggi martabat dan menjaga kehormatan diperlihatkan tokoh Dewi Anggraeni. Dewi Anggraeni dapat dikatakan sebagai wanita panutan bagi kaumnya. Dialah satusatunya perempuan yang berani menolak diperistri oleh Harjuna. Demi menjaga kehormatan dan menjaga kesetiaan pada perkawinannya dengan Ekalaya membuat ia memilih untuk bunuh diri dengan melompat ke dalam jurang.

\section{Penutup}

Menciptakan sesuatu disebut juga kreatifitas. Erich Fromm menyatakan kreativitas adalah kemampuan untuk mencipta, sebuah daya untuk mampu menciptakan sesuatu yang baru, seperti menciptakan karya yang bisa dilihat, didengar oleh orang lain (Bandem, 2001:3). Seni teater yang masuk dalam ranah seni pertunjukan berarti mencipta seni teater sama halnya dengan menciptakan tontonan bagi penikmatnya. Sebuah tontonan yang digelar tidak pernah tanpa rencana dan tujuan, artinya ia tidak dating begitu saja. Namun di dalamnya terjadi proses perenungan, perencanaan, pemikiran, dan percobaan-percobaan dengan hasil akhir suatu pertunjukan yang disuguhkan ke hadapan penonton atau khalayak.

\section{Kepustakaan}

Bandem, I Made. 2001. "Peranan Seniman Dalam Masyarakat", makalah Konggres Kebudayaan Nasional Oktober 1991 di TMII Jakarta dalam Metodologi Penciptaan Seni Program Pascasarjana ISI Yogyakarta, Yogyakarta.

Djelantik, A.A.M. 2001. Estetika Sebuah Pengantar, Bandung: MSPI dan kuBuku.

Junus, Umar. 1981. Mitos dan Komunikasi, Jakarta: Sinar Harapan.

Kosasih. R. A.. 1977. Mahabharata seri C. Pada episode Ekalaya Palastra I dan II, Kudus: CV Buana Tirta Sari.

Marianto, M Dwi. 2004. Teori Quantum, Yogyakarta: Lembaga Penelitian ISI Yogyakarta.

Nurgiyantoro, Burhan. 2002. Teori Pengkajian Fiksi, Yogyakarta: Gadjah Mada University Press.

Purwaraharja, Lephen (ed). 2000. Ideologi Teater Modern Kita, Yogyakarta: Pustaka Gondho Suli.

Rengganis, Ririe. 2004. "Sebuah Pembacaan Dekonstruksi Terhadap Cerpen Anakmu Bukanlah Anakmu, Ujar Gibran" dalam Ekspresi: Jurnal Institut Seni Indonesia Yogyakarta. Vol.10, Tahun 4, 2004

Rifa'I, Mohammad. 1978. Ilmu Fiqih Islam Lengkap, Semarang: CV. Toha Putra.

Sumardjo, Jakob. 1992. Perkembangan Teater Modern dan Sastra Drama Indonesia, Bandung: PT Citra Aditya Bakti.

Wiryamartana, I. Kuntara. 1990. Arjunawiwaha, Yogyakarta: Duta Wacana University Press.

Yudiaryani \& Hamdy Salad (ed.). 1997. Gagasangagasan Teater Garda Depan, Yogyakarta: Taman Budaya DIY,

Yudiaryani. 2002. Panggung Teater Dunia Perkembangan dan Perubahan Konvensi, Yogyakarta: Pustaka Gondho Suli. 